\title{
Instagram volksonomie as komplekse netwerke
}

Outeur:

Burgert A Senekal

\section{Affiliasie:}

Eenheid vir Taalfasilitering

en Bemagtiging

Universiteit van die Vrystaat

Korresponderende outeur: Burgert A Senekal

E-pos:

burgertsenekal@yahoo.co.uk

\section{Datums: \\ Ontvang: $\quad 08 / 05 / 20$ \\ Aanvaar: $\quad 07 / 09 / 20$ \\ Gepubliseer: 26/10/20}

Hoe om hierdie artikel aan te haal:

Burgert A Senekal,

Instagram volksonomie as komplekse netwerke, Suid-Afrikaanse Tydskrif vir Natuurwetenskap en Tegnologie 39(1) (2020). https://doi.org/10.36303/ SATNT.2020.39.1.792

\section{Kopiereg:}

(c) 2020. Authors.

Licensee: Die Suid-

Afrikaanse Akademie vir

Wetenskap en Kuns.

Hierdie werk is onder

die Creative Commons

Attribution License

gelisensieer.
Sosiale media is deel van die inligtingsontploffing en verteenwoordig groot hoeveelhede ongestruktureerde data wat deurlopend gegenereer word. Een van die maniere hoe hierdie inligting vir latere herwinning ontsluit word, is deur hutsmerke wat gebruikers self aan hul inhoud toeken. Die gebruik om self materiaal te ontsluit staan as volksonomie bekend, wat die onderwerp van hierdie studie is.

Die huidige studie ontleed die hutsmerknetwerke van 20 Suid-Afrikaanse maatskappye op Instagram. 'n Hutsmerk- of volksonomienetwerk word saamgestel deur hutsmerke as nodusse voor te stel en 'n skakel tussen hutsmerke aan te dui indien hulle in dieselfde plasing voorkom. Komplekse netwerkstatistieke word vir hierdie netwerke bereken, insluitend die gemiddelde digtheid, gemiddelde pad en gemiddelde oorganklikheid van hierdie netwerke, en hulle word met mekaar vergelyk. Daar word aangetoon dat hierdie netwerke oorwegend kleinwêreldnetwerke is wat gekenmerk word deur' $n$ kort gemiddelde pad wat soortgelyk is aan 'n Erdös en Rényi lukrake netwerk (ER- netwerk), maar dat oorganklikheid aansienlik hoër is as vir ekwivalente ER-netwerke. Daar word ook aangetoon dat vir $90 \%$ van hierdie netwerke, kleinwêreldsheid (S) $>3$ is, wat beteken dat hierdie netwerke ook kleinwêreldnetwerke is volgens die kleinwêreldsheidsindeks.

Sleutelwoorde: Instagram, sosiale media, volksonomie, hutsmerke, komplekse netwerke, kleinwêreldsheid, inligtingsklassifikasie

Instagram folksonomy as complex networks: Social media is part of the information explosion and represents large amounts of unstructured data that is generated continuously. One of the ways this information is categorised for later retrieval is through hashtags that users assign to their own content. This practice of categorising material is known as folksonomy, which is the subject of the current study.

The current study analyses the hashtag networks of 20 South African companies on Instagram. A hashtag or folksonomy network is compiled by representing hashtags as nodes and indicating a link between hashtags if they occur in the same post. Complex network statistics are calculated for these networks, including the density, average path length, and average transitivity, and they are compared with each other. These networks are shown to be predominantly small-world networks characterised by a short average path length similar to an Erdös and Rényi random network (ER network), but transitivity is significantly higher than for equivalent ER networks. It is also shown that for $90 \%$ of these networks, small-worldness $(S)>3$, which means that these networks are also small-world networks according to the small-world index.

Keywords: Instagram, social media, folksonomy, hashtags, complex networks, small worlds, information classification

\section{Inleiding}

Sosiale media het 'n ingrypende invloed gehad op hoe mense met mekaar kommunikeer en met hul leefwêreld omgaan. Een groot verandering wat sosiale media en Web 2.0 meegebring het, is die toenemende belangrikheid van gebruiker-gegenereerde inhoud. Gebruikergegenereerde sosiale media-inhoud het oor die afgelope jare byvoorbeeld 'n belangrike faktor geword wat verbruikersgedrag beïnvloed (Jaakonmäki, Müller en Vom Brocke 2017), en boonop het sosiale media die geleentheid geskep vir mense om self inligting te klassifiseer deur middel van hutsmerke ("hashtags"), wat die onderwerp van die huidige studie is.

Shen en Wu (2005), Noruzi (2006), Cattuto et al. (2007), Xamena, Brignole en Maguitman (2017) en Monechi et al. (2017) verwys na die verskynsel waar mense self kategorieë aan inhoud op sosiale media toeken as volksonomie. Die term is geskep deur Van der Wal (sien Van der Wal, 2007), wat die konsep soos volg omskryf: 
Folksonomy is the result of personal free tagging of information and objects (anything with a URL) for one's own retrieval. The tagging is done in a social environment (usually shared and open to others). Folksonomy is created from the act of tagging by the person consuming the information.

Xamena, Brignole en Maguitman (2017), Ibba, Orrù, Pani en Porru (2015), Cattuto et al. (2007) en Shen en Wu (2005), stel voor dat sulke etikette netwerke vorm wat as komplekse netwerke ontleed kan word, en dat volksonomienetwerke ook kleinwêreldnetwerke ('n subkategorie van komplekse netwerke) is soos deur Watts en Strogatz (1998) gemodelleer. Nie een van hierdie outeurs ontleed egter hutsmerke op Instagram nie en hulle baseer hul gevolgtrekkings op die ontleding van een of twee datastelle, wat hul bevindinge nie veralgemeenbaar maak nie. Verder skat hulle die waarde van die gemiddelde pad in 'n lukrake netwerk én van kleinwêreldsheid, maar daar bestaan meer akkurate meetinstrumente binne die netwerkteorie, soos ook in die huidige artikel bespreek word.

In die huidige studie word 20 hutsmerknetwerke, soos saamgestel uit die plasings van 20 Suid-Afrikaanse maatskappye op Instagram, ontleed. Die doel is om te bepaal wat die kenmerke van hutsmerknetwerke op Instagram teen die agtergrond van die teorie van komplekse netwerke is, met spesifieke verwysing na digtheid en die kleinwêreldsheidverskynsel. Netwerkstatistieke soos die digtheid van netwerke $(d)$, hul gemiddelde pad $(L)$ en oorganklikheid (C) word ontleed, en daar word deur middel van 'n vergelyking met Erdös en Rényi (1960) se lukrake netwerkmodel, en aan die hand van Humphries en Gurney (2008) se kleinwêreldsheidsindeks (S), aangedui dat hutsmerknetwerke wel kwantitatief aantoonbare kleinwêreldnetwerke is (dié terme word in die huidige artikel bespreek).

Die artikel is soos volg gestruktureer. Eerstens word 'n agtergrond oor hutsmerke op sosiale media platforms verskaf, met spesifieke verwysing na Instagram. Daarna word metings binne die netwerkteorie bespreek. Hierop volg 'n uiteensetting van die dataversamelings- en verwerkingsmetodes, waarna die 20 netwerke ontleed word. Die artikel sluit af met samevattende opmerkings en voorstelle vir verdere navorsing.

\section{Agtergrond}

Sosiale media is deel van die inligtingsontploffing en grootdataverskynsel en verteenwoordig groot hoeveelhede ongestruktureerde data wat deurlopend gegenereer word. Daar word daagliks 100 miljoen foto's en video's op Instagram gelaai, die platform word daagliks deur 500 miljoen gebruikers besoek, en daar is reeds meer as 50 miljard foto's op hierdie platform gelaai (Aslam, 2020). Om sulke groot volumes inligting te organiseer en te ontsluit sodat dit later herwin kan word, is ' $n$ beduidende uitdaging en hierin speel die hutsmerk ' $n$ noemenswaardige rol.
Hutsmerke het op Twitter ontstaan na Chris Messina, 'n ontwerper, sy volgelinge in Augustus 2007 gevra het hoe hulle daaroor voel om die pondteken (\#) vir groepgesprekke te gebruik (Giannoulakis en Tsapatsoulis, 2016; Kolowich, 2014). Die idee het gou aanklank gevind by 'n groot groep gebruikers en teen Julie 2009 het Twitter hutsmerke amptelik erken. Instagram het hutsmerke in Januarie 2011 by die funksionaliteit van dié sosiale media platform gevoeg (Giannoulakis en Tsapatsoulis, 2016) en later in dié jaar is hutsmerke op Twitter gebruik om gesprekke rondom die Arabiese Lente te organiseer (Kolowich, 2014). In Suid-Afrika is hutsmerke onder andere bekend vir studente opstande in 2015/2016 rondom hutsmerke op sosiale media soos \#RhodesMustFall, \#FeesMustFall, \#AfrikaansMustFall en \#OpenStellenbosch (sien byvoorbeeld Kusá 2018).

Hutsmerke is etikette of woorde wat voorafgegaan word deur' $n\langle \#\rangle$ en word hoofsaaklik gebruik om die inhoud van 'n plasing aan te dui, wat gebruikers toelaat om plasings te soek en die sigbaarheid van 'n plasing te verhoog (Giannoulakis en Tsapatsoulis, 2016). Die doel van hutsmerke is met ander woorde primêr om inligting te organiseer sodat dit agterna herwin kan word (Giannoulakis en Tsapatsoulis 2016, kyk ook Erz, Marder, en Osadchaya 2018 en Ibba et al. 2015).

Hutsmerke funksioneer op dieselfde manier op Instagram as op Twitter, naamlik dat hutsmerke primêr 'n beskrywing van die inhoud van 'n plasing verskaf. Giannoulakis en Tsapatsoulis (2016) toon aan dat in 66\% van gevalle hutsmerke op Instagram ooreenstem met die inhoud van 'n foto, terwyl die res van gevalle dui op ander assosiasies van die gebruiker. Dorsch (2018) vind ook dat hutsmerke in die meerderheid van gevalle $(60 \%)$ ' $n$ aanduiding is van die inhoud van ' $n$ foto op Instagram. In die oorblywende gevalle verwys foto's na meta-inligting (byvoorbeeld die datum, plek of soort foto) (15\% van gevalle), hutsmerke verwant aan Instagram (byvoorbeeld \#instagood) (7\%), 'n oproep om handeling (byvoorbeeld \#followmearound) $(7 \%)$ en ander.

Hutsmerke word veral gebruik om die sigbaarheid van 'n plasing op Instagram te verhoog, wat lei tot meer gebruikersreaksies (voorkeure en kommentare) en volgelinge (Terttunen, 2017; Ibba, et al., 2015). Hutsmerke maak ook plasings sigbaar in die Verkenningsblad ("Explore page"), wat tot verdere sigbaarheid lei (Ibba, et al., 2015). Navorsing het reeds getoon dat deur slegs een hutsmerk te gebruik, gebruikersreaksies gemiddeld met $12,6 \%$ verhoog word (Erz, Marder, en Osadchaya, 2018) en deur twee hutsmerke te gebruik, gebruikersreaksies gemiddeld met $56 \%$ verhoog word (Kleintjes, 2017). Ye et al. (2018) vind ook 'n sterk positiewe korrelasie tussen die aantal hutsmerke en gebruikersreaksies op 'n plasing. Instagram laat 30 hutsmerke per plasing toe. 
Maatskappye skep ook hul eie hutsmerke om gebruikersreaksies aan te moedig (Kleintjes, 2017; Bergström en Bäckman, 2013). Kliënte word dan aangemoedig om die maatskappy se hutsmerk in hul eie plasings te gebruik, byvoorbeeld 'n foto plasing van 'n persoon langs sy Ford wat geplaas word met \#ford, wat dan die sigbaarheid van die maatskappy verhoog deur die maatskappy se naam sigbaar te maak vir die volgelinge van die gebruiker (Bergström en Bäckman, 2013).

Soos in die inleiding gestel, staan die verskynsel waar mense etikette aan aanlyn-inhoud toeken as volksonomie ("folksonomy") bekend. Volksonomie kan volgens Shen en $\mathrm{Wu}(2005)$ beskou word as 'n netwerk waar nodusse die etikette voorstel en verskillende etikette wat aan een inhoudsitem toegewys is, deur skakels gekoppel word. Kyk byvoorbeeld na die volgende plasing van Frontrunner (Suid-Afrika) op Instagram, soos geplaas op 15 April 2020:

Soon we will go where there are no roads

\#frontrunner \#frontrunnerza \#borntoroam

Photo Credit: @tobiaswoggon \#4wdlife \#overland \#overlanding \#campeveryday \#camping \#roofrack \#wanderlust \#allterrainvehicle \#offroadvehicle \#offroadadventure \#4wdactionaustralia \#defender \#landroverdefender \#defender110 @landroversa @ landrover_journal \#landroversa \#lightbar

Hier kom 19 verskillende hutsmerke voor. Wanneer 'n hutsmerknetwerk saamgestel word, sal daar byvoorbeeld 'n skakel wees tussen \#frontrunner en \#frontrunnerza, tussen \#frontrunner en \#borntoroam, en tussen \#frontrunnerza en \#borntoroam. So sal daar 'n skakel tussen elke hutsmerk aangedui word.

Soos in die inleiding gestel, ondersoek Shen en $\mathrm{Wu}$ (2005), Cattuto et al. (2007), Monechi et al. (2017) en Xamena, Brignole en Maguitman (2017) volksonomienetwerke, maar nie een van hierdie studies het ondersoek ingestel na hutsmerke op Instagram nie en hulle maak gebruik van die skatting van die gemiddelde pad vir lukrake netwerke en die skatting van kleinwêreldsheid. Shen en Wu (2005) en Pan et al. (2016) ondersoek die netwerk van etikette op Del. icio.us ('n sosiale boekmerkplatform wat nie meer in gebruik is nie), Cattuto et al. (2007) ondersoek Del.icio.us en BibSonomy ('n akademiese boekmerkplatform waar gebruikers artikels kan deel), Xamena, Brignole en Maguitman (2017) ondersoek DMOZ ('n boekmerkplatform wat nie meer in gebruik is nie), Monechi et al. (2017) ondersoek Last.fm ('n musiek platform) en Li en Zhang (2020) ondersoek volksonomienetwerke op Steam ('n aanlyn platform waar mense speletjies kan deel).

Die huidige studie ontleed 20 netwerke wat vanaf Instagram saamgestel is, gebruik die presiese berekening van die gemiddelde pad in lukrake netwerke, soos voorgestel deur
Fronczak, Fronczak en Holyst (2004), en maak gebruik van die kwantitatiewe definisie van kleinwêreldsheid $(S)$, soos voorgestel deur Humphries en Gurney (2008). Die volgende afdeling bespreek hoe netwerkstatistieke bereken is.

\section{Kleinwêreldsheid in komplekse netwerke}

Die digtheid van 'n netwerk, die gemiddelde pad en die mate van oorganklikheid het almal betrekking op die verspreiding van inligting in 'n komplekse netwerk. Verder is die gemiddelde pad en oorganklikheid nodig om 'n netwerk as 'n kleinwêreldnetwerk te klassifiseer na hierdie waardes vir die netwerk met ' $n$ lukrake netwerk vergelyk is. Hierdie meetinstrumente word in die huidige afdeling bespreek.

\section{Digtheid $(\delta)$}

Inligting versprei vinniger in netwerke met ' $n$ hoër digtheid (Himelboim et al., 2017). Digtheid $(\delta)$ meet die getal skakels $(m)$ tussen nodusse $(n)$ in die netwerk teenoor die aantal moontlike skakels (Schnelle, 2018; Himelboim et al., 2017). Die digtheid van die netwerk of grafiek $(\delta(\mathrm{G}))$ word met behulp van Vergelyking (1) bereken (Humphries en Gurney, 2008), waar $\langle k\rangle$ dui op die gemiddelde getal skakels in die netwerk, $n$ dui op die getal nodusse en $m$ dui op die getal skakels in die netwerk.

$$
\delta(G)=\frac{2 m}{n(n-1)}=\frac{\langle k\rangle}{(n-1)}
$$

Wanneer $\langle k\rangle<<n$ word die netwerk as swak verbind ("sparse") geklassifiseer, wat ook beteken dat $\delta \ll 1$ (Estrada, 2012). Die meerderheid werklike netwerke is swak verbind (Latapy, Magnien, en Del Vecchio, 2008).

\section{Gemiddelde pad (L)}

Die gemiddelde pad in 'n netwerk is ook ' $n$ aanduiding van hoe maklik inligting binne 'n netwerk kan versprei. ' $n$ Pad in 'n netwerk verwys na die kortste aantal stappe wat geneem moet word om 'n nodus vanaf ' $n$ ander nodus te bereik (Senekal, 2015, Borge-Holthoefer en Arenas, 2010). Die gemiddelde pad in 'n netwerk $(L)$ word bereken met Vergelyking (2) (Liang et al., 2009), waar $d_{i j}$ die kortste pad tussen nodusse $i$ en $j$ aandui en $N$ dui die totale getal nodusse in die netwerk aan.

$$
L=\frac{2 \sum_{i>j} d_{i j}}{N(N-1)}
$$

Die gemiddelde pad word ook saam met groepsvorming $\left(C^{W S}\right)$ of oorganklikheid $\left(C^{\Delta}\right)$ (sien verderaan) gebruik om 'n netwerk as 'n kleinwêreldnetwerk te klassifiseer. Ten einde 'n netwerk sodanig te klassifiseer, moet die werklike netwerk met 'n lukrake netwerk vergelyk word en die model wat gewoonlik vir hierdie vergelyking aangewend word, is Erdös en Rényi (1960) se lukrake netwerkmodel (ER-model) (Senekal, 2015). Fronczak, Fronczak en Holyst (2004) wys egter dat die gemiddelde pad in ER-netwerke $\left(L_{E R}\right)$ nie presies gedefinieer is nie, maar gewoonlik geskat word soos in Vergelyking (3), waar $N$ die getal nodusse in die 
netwerk aandui en $\langle k\rangle$ die gemiddelde getal skakels in die netwerk (sien ook byvoorbeeld Shen en Wu, 2005 en Humphries en Gurney, 2008).

$$
L_{E R} \sim \frac{\ln N}{\ln \langle k\rangle}
$$

Fronczak, Fronczak en Holyst (2004) wys dat 'n meer presiese formulering van $L_{E R}$ in Vergelyking (4) vervat kan word.

$$
L_{E R}=\frac{\ln N-\gamma}{\ln \langle k\rangle}+\frac{1}{2}
$$

In die berekening van die gemiddelde pad in ER netwerke hieronder word gebruik gemaak van Vergelyking (4).

\section{Groepsvorming en gemiddelde oorganklikheid ( $\mathrm{C}^{\mathrm{ws}}$ en $\mathrm{C}^{\Delta}$ )}

Groepsvorming ("clustering" of $C^{W S}$ ) is deur Watts en Strogatz (1998) geformuleer en meet die getal skakels wat tussen die bure van 'n nodus gevind word, in vergelyking met die getal moontlike skakels (Zhou et al., 2008). Groepsvorming kan met Vergelyking (5) bereken word (Liang et al., 2009; Peng et al., 2008; Zhou et al., 2008; Shen en Wu, 2005), waar $E_{i}$ na die getal skakels tussen die bure van nodus $i$ verwys, en $k_{i}$ na die getal skakels van nodus $i$ verwys.

$$
C_{i}=\frac{2 E_{i}}{k_{i}\left(k_{i}-1\right)}
$$

Die gemiddelde groepsvorming $\left(C^{W S}\right)$ is die gemiddeld van $C_{i}$ vir al die nodusse in die netwerk (Heidtmann, 2013).

Verwant aan $C^{W S}$ is oorganklikheid ("transitivity"), wat die aantal driehoeke en drietalle in 'n netwerk vergelyk, waar 'n driehoek 'n stel van drie nodusse is waar 'n skakel tussen al drie voorkom en 'n drietal ' $n$ stel van drie nodusse is waar slegs twee skakels voorkom. Kyk byvoorbeeld na Figuur 1. Hier kan 'n skakel tussen nodusse A en B, A en C en $B$ en $C$ gesien word, wat 'n driehoek vorm. Daar is ook 'n skakel tussen $C$ en $D$ en tussen $C$ en $E$, maar omdat daar nie ' $n$ skakel is tussen D en E nie, is hierdie 'n drietal.

Oorganklikheid $\left(C^{\Delta}\right)$ word met Vergelyking (6) bereken (Newman, 2010, Humphries en Gurney, 2008).

$$
C^{\Delta}=\frac{3 \times \text { aantal driehoeke in die netwerk }}{\text { aantal drietalle in die netwerk }}
$$

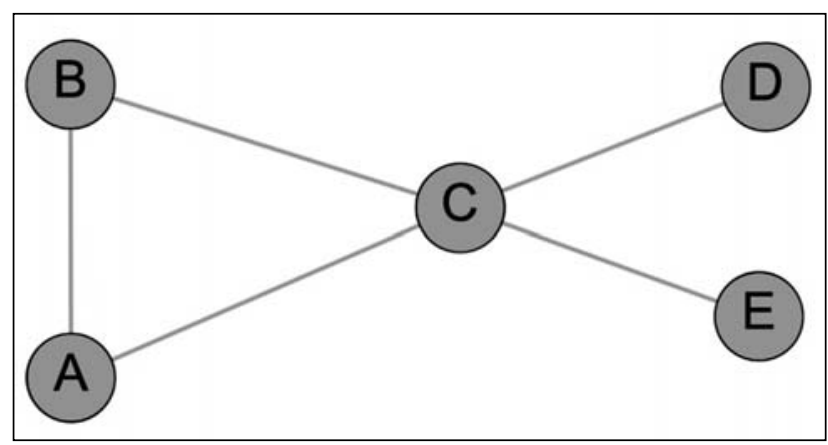

FIGUUR 1: 'n Voorbeeldnetwerk
$C^{W S}$ en $C^{\Delta}$ lewer soortgelyke maar nie identiese resultate nie en kan soms baie verskil (Humphries en Gurney, 2008). In navolging van Humphries en Gurney (2008) verkies ek $C^{\Delta}$ en laat hierna die $D$ weg en verwys na $C^{\Delta}$ as $C$.

Vir ER-netwerke stel Shen en Wu (2005) Vergelyking (7) voor om oorganklikheid mee te bereken.

$$
C_{E R} \simeq \frac{\langle k\rangle}{N}
$$

In die berekenings hieronder word Vergelyking (7) gebruik om $C_{E R}$ mee te bereken.

\section{Kleinwêreldsheid (S)}

Om 'n netwerk as 'n kleinwêreldnetwerk te klassifiseer, moet die waardes van $L$ en $C$ vir die netwerk vergelyk word met hierdie waardes vir 'n gelykwaardige netwerk wat met die ER-model (Erdös en Rényi, 1960) saamgestel is, wat noteer kan word as onderskeidelik $L_{E R}$ en $C_{E R}$ (Peng, et al., 2008). 'n Gelykwaardige netwerk verwys hier na Erdös en Rényi se $G(n, m)$-model, waar die getal nodusse $(n)$ en skakels $(m)$ in die model gelyk is aan dié van die oorspronklike netwerk, maar skakelvorming vind lukraak plaas. 'n Kleinwêreldnetwerk word gewoonlik as sulks gedefinieer wanneer $L \approx L_{E R^{\prime}}$ maar $C>>C_{E R}$ (Solé, et al., 2010, Peng, et al., 2008, Liang, et al., 2009, Shen en Wu, 2005, i Cancho en Solé, 2001). Daar is egter nie 'n presiese afsnypunt, byvoorbeeld dat 'n verskil van $10 \%$ soortgelyk is maar $50 \%$ as beduidend geag word nie.

Humphries en Gurney (2008) kritiseer hierdie vae definisie van kleinwêreldnetwerke en stel voor dat kleinwêreldsheid presies gekwantifiseer kan word met Vergelykings (8), (9) en (10).

$$
\begin{gathered}
\gamma=\frac{C}{C_{E R}} \\
\lambda=\frac{L}{L_{E R}} \\
S=\frac{\gamma}{\lambda}
\end{gathered}
$$

Volgens Humphries en Gurney (2008) is 'n netwerk 'n kleinwêreldnetwerk indien $S>1$, maar wanneer $1 \leq S \leq 3$ is die netwerk volgens hulle ' $n$ grensgeval, wat beteken dat wanneer $S>3$ is die netwerk ' $n$ duidelike kleinwêreldnetwerk.

Om kleinwêreldsheid te bereken, word die volgende stappe met ander woorde gevolg:

1. die netwerk word saamgestel met nodusse $(n)$ en skakels $(m)$;

2. die gemiddelde pad $(L)$ word vir die netwerk bereken met Vergelyking (2);

3. die netwerk se groepsvorming $\left(C^{W S}\right)$ of oorganklikheid $\left(C^{\Delta}\right)$ word bereken, soos met Vergelykings (5) of (6);

4. 'n ER-model met dieselfde $n$ en $m$ as die netwerk word saamgestel en $L_{E R}$ word bereken, soos met Vergelyking (3) of (4) (4 in die huidige studie, maar gewoonlik 3); 
5. $\quad C_{E R}$ word bereken, soos met Vergelyking (7);

6. $L$ word vergelyk met $L_{E R}$ en $C\left(C_{W S}\right.$ of $\left.C^{\Delta}\right)$ met $C_{E R^{\prime}}$ soos in Vergelykings (8), (9) en (10).

Die volgende afdeling bespreek hoe data versamel en verwerk is.

\section{Metodes}

Die Instagram plasings van 20 Suid-Afrikaanse maatskappye is op 30 April 2020 met behulp van InstaBro versamel en in Google Sheets ingevoer. Alle plasings van al 20 maatskappye is versamel. Hierna is die volgende gereelde uitdrukking self geskep om die hutsmerke uit die byskrifte van plasings te onttrek, waar die plasing se byskrif op die spreivel "Instagram" in Kolom $\mathrm{E}$ is:

\section{$=$ ARRAYFORMULA $($ TRIM $($ LOWER $($ SPLIT $($ REGEXR \\ E P L A C E ( I n s t a g r a m ! E 2 : E, " $((\wedge \mid \backslash \mathrm{s})$ $\left.[\wedge \#] \backslash S^{*}\right) \mid\left([\wedge \# \backslash W \backslash S] \backslash S^{*}\right)^{\prime \prime}$, ,"')," “))))}

Hierdie gereelde uitdrukking het dit moontlik gemaak om elke hutsmerk in 'n aparte sel maar in dieselfde ry te stoor, wat die konstruksie van 'n hutsmerkernetwerk bemiddel het. Sodoende kan 'n skakel tussen elke hutsmerk met behulp van netwerkontledingsprogrammatuur soos Gephi aangedui word indien hulle in dieselfde plasing voorkom. Tabel 1 dui die maatskappye en die getal plasings aan wat versamel is. Hierdie maatskappye is gekies omdat hulle 'n wye verskeidenheid sektore verteenwoordig: supermarkte (Checkers en Pick n Pay), algemene toebehore (Makro, Game en Kloppers), buitelewe winkels (Outdoor Warehouse, First Ascent, Frontrunner en K-Way), klere (Due South), 'n boekwinkel (Exclusive Books), huisversiering (@ Home), uitgewers (Lapa, NB Uitgewers en Protea Boekhuis), selfoonmaatskappye (MTN en Vodacom), restaurante (Mugg \& Bean en Spur) en 'n kosmetiese besigheid (Buffelsfontein Baardolie). Hierdie maatskappye behoort 'n uiteen-

\begin{tabular}{|c|c|c|c|}
\hline Maatskappyrekening & Getal plasings & \# hutsmerke & $\begin{array}{c}\text { \# unieke } \\
\text { hutsmerke }\end{array}$ \\
\hline 1. @buffelsfontein_baard_olie & 501 & 105 & 52 \\
\hline 2. @checkers_sa & 588 & 1355 & 524 \\
\hline 3. @duesouthsa & 424 & 1940 & 423 \\
\hline 4. @exclusivebooks & 1619 & 2198 & 834 \\
\hline 5. @firstascentsa & 1296 & 1793 & 376 \\
\hline 6. @frontrunnerza & 642 & 7851 & 1447 \\
\hline 7. @gamestores_sa & 141 & 224 & 107 \\
\hline 8. @homewarestore & 815 & 1566 & 839 \\
\hline 9. @klopperssa & 323 & 2674 & 953 \\
\hline 10. @kwaysa & 1781 & 4677 & 561 \\
\hline 11. @lapa_uitgewers & 484 & 1508 & 589 \\
\hline 12. @makro_sa & 157 & 75 & 37 \\
\hline 13. @mtnza & 1016 & 1815 & 337 \\
\hline 14. @mugg_and_bean & 867 & 1316 & 368 \\
\hline 15. @nbpublishers & 363 & 1283 & 602 \\
\hline 16. @outdoorwarehouseza & 264 & 1148 & 274 \\
\hline 17. @picknpay & 1016 & 4388 & 942 \\
\hline 18. @proteaboekhuis & 237 & 3322 & 1100 \\
\hline 19. @spursteakranches & 194 & 433 & 200 \\
\hline 20. @vodacom & 1146 & 1841 & 392 \\
\hline
\end{tabular}

lopende verskeidenheid hutsmerkgebruike sowel as bemarkingstrategieë op Instagram te hê, alhoewel dit nie moontlik is om alle sektore van die Suid-Afrikaanse ekonomie in slegs 20 netwerke te verteenwoordig nie.

Na die hutsmerke onttrek is, is dit ingevoer in Gephi, 'n netwerkontledingsprogram wat dit moontlik maak om onder andere $L, C^{W S}$ en $C^{\Delta}$ vir elke netwerk te bereken.

Hier is nie ruimte om elke hutsmerknetwerk visueel voor te stel nie, maar as 'n voorbeeld stel Figuur 2 die hutsmerknetwerk van Frontrunner voor. Omdat hierdie netwerk die meeste nodusse (hutsmerke) en die meeste skakels het (sien volgende afdeling), wys hierdie netwerk hoe verwikkeld 'n volksonomie kan wees. As gevolg van ruimtebeperkings is etikette nie vertoon nie. Figuur 2 illustreer dat hutsmerkernetwerke te verwikkeld en te kompleks is om visueel mee om te gaan, wat die berekeninge verder in hierdie artikel noodsaak.

Die volgende afdeling verskaf die resultate van die huidige studie.

\section{Resultate}

Tabel 2 verskaf 'n opsomming van die resultate van die huidige studie. Die aantal nodusse $(n)$, aantal skakels $(m)$, gemiddelde aantal skakels $(\langle k\rangle)$, digtheid $(\delta)$, gemiddelde pad $(L)$, gemiddelde pad vir die ER-model $\left(L_{E R}\right)$, groepsvorming $\left(C\right.$, met ander woorde $\left.C^{\Delta}\right)$, groepsvorming vir die ER-model $\left(C_{E R}\right)$, en kleinwêreldsheid $(S)$ is aangedui. Tabel 2 is alfabeties rangskik.

Daar is 20 hutsmerknetwerke in hierdie datastel. Die getal nodusse lê in die spektrum $19 \leq n \leq 1450$ en die getal skakels tussen $11 \leq m \leq 3221$, terwyl die gemiddelde getal skakels tussen 1,16 $\leq\langle k\rangle \leq 4,55$ lê. Die Outdoor Warehouse hutsmerknetwerk het die hoogste gemiddelde getal skakels

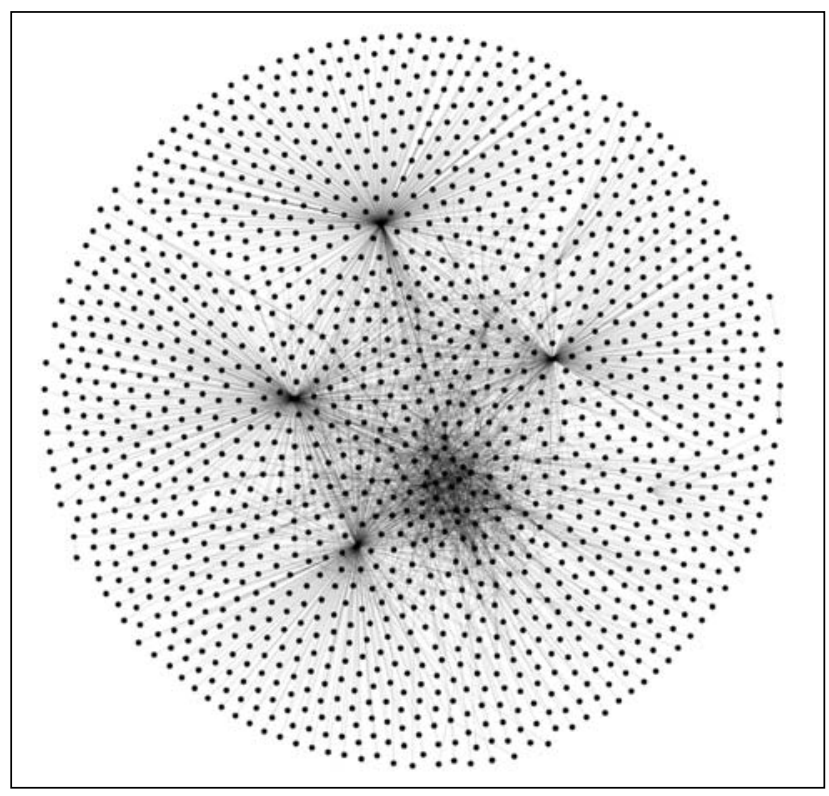

FIGUUR 2: Die hutsmerknetwerk van Frontrunner 
TABEL 2: 'n Opsomming van die resultate van die huidige studie

\begin{tabular}{|c|c|c|c|c|c|c|c|c|c|}
\hline Netwerk & $n$ & $m$ & $\langle k\rangle$ & $\delta$ & $L$ & $L_{E R}$ & $c$ & $C_{E R}$ & $s$ \\
\hline @Home & 816 & 1109 & 2.72 & 0.0033 & 5.29 & 6.63 & 0.108 & 0.003 & 16.21 \\
\hline Buffelsfontein Baardolie & 25 & 29 & 2.32 & 0.0967 & 2.92 & 3.64 & 0.421 & 0.093 & 2.27 \\
\hline Checkers & 496 & 670 & 2.70 & 0.0055 & 5.15 & 6.16 & 0.212 & 0.005 & 19.46 \\
\hline Due South & 421 & 684 & 3.25 & 0.0077 & 3.03 & 5.14 & 0.440 & 0.008 & 28.50 \\
\hline Exclusive Books & 784 & 1022 & 2.61 & 0.0033 & 3.40 & 6.85 & 0.146 & 0.003 & 21.95 \\
\hline First Ascent & 341 & 507 & 2.97 & 0.0087 & 3.10 & 5.32 & 0.428 & 0.009 & 24.54 \\
\hline Frontrunner & 1450 & 3221 & 4.44 & 0.0031 & 2.96 & 4.99 & 0.495 & 0.003 & 80.78 \\
\hline Game & 95 & 84 & 1.77 & 0.0188 & 2.10 & 7.48 & 0.307 & 0.019 & 8.25 \\
\hline K-Way & 523 & 823 & 3.15 & 0.0060 & 2.84 & 5.46 & 0.526 & 0.006 & 43.70 \\
\hline Kloppers & 954 & 1895 & 3.97 & 0.0042 & 3.64 & 5.06 & 0.354 & 0.004 & 42.50 \\
\hline Lapa Uitgewers & 577 & 824 & 2.86 & 0.0050 & 3.52 & 6.01 & 0.321 & 0.005 & 32.42 \\
\hline Makro & 19 & 11 & 1.16 & 0.0643 & 1.27 & 16.65 & 0.000 & 0.061 & 0.00 \\
\hline MTN & 300 & 352 & 2.35 & 0.0078 & 5.01 & 6.51 & 0.384 & 0.008 & 24.55 \\
\hline Mugg en Bean & 310 & 516 & 3.33 & 0.0108 & 3.77 & 4.79 & 0.372 & 0.011 & 17.32 \\
\hline NB Uitgewers & 585 & 894 & 3.06 & 0.0052 & 4.06 & 5.69 & 0.160 & 0.005 & 15.31 \\
\hline Outdoor Warehouse & 271 & 617 & 4.55 & 0.0169 & 2.77 & 3.81 & 0.560 & 0.017 & 16.66 \\
\hline Pick N Pay & 925 & 1882 & 4.07 & 0.0044 & 2.95 & 4.96 & 0.503 & 0.004 & 57.17 \\
\hline Protea Boekhuis & 1115 & 1581 & 2.84 & 0.0025 & 2.65 & 6.68 & 0.774 & 0.003 & 152.16 \\
\hline Spur Steak Ranches & 181 & 234 & 2.59 & 0.0144 & 3.91 & 5.36 & 0.253 & 0.014 & 8.86 \\
\hline Vodacom & 324 & 414 & 2.56 & 0.0079 & 5.22 & 6.05 & 0.350 & 0.008 & 22.19 \\
\hline
\end{tabular}

$(\langle k\rangle=4,55)$, terwyl die Makro hutsmerknetwerk die laagste gemiddelde getal skakels het $(\langle k\rangle=1,16)$.

Die gemiddelde digtheid is $\delta=0,015$, met $0,003 \leq \delta \leq$ 0,097. Die Buffelsfontein Baardolie hutsmerknetwerk het die hoogste digtheid $(\delta=0,097)$ en die Protea Boekhuis hutsmerknetwerk het die laagste digtheid $(\delta=0,0025)$. Al 20 netwerke het ' $\mathrm{n}$ digtheid onder $\delta=0,1$, wat beteken hierdie netwerke is swak verbind. ' $n$ Lae digtheid is met ander woorde kenmerkend van hierdie hutsmerknetwerke.

Die gemiddelde pad $(L)$ vir al die netwerke is $L=3,48$, wat binne die spektrum 1,27 $\leq L \leq 5,29$ lê en met ander woorde kort is (hierdie waarde word eers werklik betekenisvol wanneer dit met $L_{E R}$ vergelyk word, sien verderaan). Die @ Home hutsmerknetwerk het die hoogste gemiddelde pad $(L=5,29)$ en die Makro hutsmerknetwerk het die laagste gemiddelde pad $(L=1,27)$. Soos met ander netwerke word hutsmerknetwerke dus ook gekenmerk deur'n gemiddelde kort pad tussen nodusse.

Die gemiddelde oorganklikheid vir al die netwerke is $C=$ 0,36 en lê binne die spektrum $0 \leq C \leq 0,77$, wat nie uitsonderlik hoog is nie maar hoër is as wat verwag sou word indien skakelvorming lukraak plaasgevind het (hierdie waarde word eers werklik betekenisvol wanneer dit met $C_{E R}$ vergelyk word, sien verderaan). Die Protea Boekhuis hutsmerknetwerk het die hoogste oorganklikheid $(C=0,77)$ en die Makro hutsmerknetwerk het die laagste oorganklikheid $(C=0)$. Die oorganklikheid van $C=0$ vir die Makro hutsmerknetwerk is uitsonderlik laag, maar die vergelyking hieronder toon dat $C$ steeds gemiddeld veel hoër is as $C_{E R}$.

Aangesien $L$ gemiddeld $43,55 \%$ laer is as $L_{E R}\left(L_{E R}=6,16\right.$ teenoor $L=3,48$ ), is $L \approx L_{E R}$. Neem in ag dat daar nie 'n duidelik geformuleerde afsnypunt vir "soortgelyk" of "baie groter" is nie, en daarom gebruik ek die verskil tussen $C$ en $C_{E R}$ as verwysingspunt. $C$ is gemiddeld $2363,31 \%$ hoër as $C_{E R}\left(C_{E R}=0,01\right.$ teenoor $\left.C=0,36\right)$, en dus is $C>>C_{E R^{\prime}}$ wat hierdie netwerke as kleinwêreldnetwerke klassifiseer volgens die standaard definisie. Meer presies is $0 \leq S \leq$ 152,16 . Vir 18 netwerke ( $90 \%$ van die totaal) is $S>3$ en is hulle dus kleinwêreldnetwerke, maar daar is ook 1 grensgeval (Buffelsfontein Baardolie) $(1 \leq S \leq 3)$ en 1 (Makro) wat nie 'n kleinwêreldnetwerk is nie met $S<1$.

Die volgende afdeling bespreek hierdie resultate.

\section{Bespreking}

Tabel 2 toon duidelik aan dat die meerderheid hutsmerknetwerke wat hier ondersoek is kleinwêreldnetwerke is. Die enigste uitsondering hier is die Makro hutsmerknetwerk, wat baie klein is $(m=11)$ en ook geen oorganklikheid $(C=0)$ het nie. Inligtingsnetwerke het gewoonlik'n laer oorganklikheid as sosiale netwerke, maar 'n oorganklikheid van $C=0$ is ongewoon en is hier die gevolg van die baie klein netwerk. Ook in die geval van Buffelsfontein Baardolie is die hutsmerknetwerk baie klein $(m=29)$, alhoewel hier 'n nie-zero oorganklikheid bereken is en die netwerk as ' $n$ grensgeval geklassifiseer is. Daar kan met ander woorde aangetoon word dat hutsmerknetwerke op Instagram ook kleinwêreldnetwerke is, mits hulle ten minste 'n nie-zero oorganklikheid het.

Xamena, Brignole en Maguitman (2017) merk dat alle kennis op een of ander manier verbind is en dat ' $n$ kleinwêreldargitektuur dit moontlik maak om maklik tussen onderwerpe te beweeg. Cattuto et al. (2007) voer op hul beurt aan dat die kleinwêreldargitektuur van volksonomienetwerke dit makliker maak om interessante inhoud te vind. Die kleinwêreldargitektuur van hierdie Instagram hutsmerknetwerke fasiliteer met ander woorde die opspoor van inligting en die navigasie tussen onder- 
werpe - iets wat toenemend belangrik word gegewe die groot volume inhoud wat daagliks op hierdie platform geplaas word.

Die merkwaardigheid van kleinwêreldsheid is dat hierdie 20 maatskappye nie saamwerk om plasings op Instagram te maak en hutsmerke te kies nie. Volksonomie ontstaan spontaan wanneer gebruikers (hier maatskappye) self etikette aan inhoud toeken en selfs met spontane gedrag vertoon al hierdie netwerke ooreenstemmende kenmerke ten opsigte van netwerkstruktuur; Cattuto, et al. (2007) noem volksonomie "conceptual structures created by the people." Boonop is daar reeds in 'n verskeidenheid soorte netwerke aangetoon dat kleinwêreldsheid 'n algemene kenmerk van komplekse netwerke is (Senekal, 2015, Cattuto, et al., 2007), en volksonomienetwerke op Instagram kan met ander woorde by hierdie lys gevoeg word.

\section{Gevolgtrekking}

Die huidige studie het gebruik gemaak van 20 hutsmerknetwerke wat saamgestel is uit Suid-Afrikaanse maatskappye se plasings op Instagram. Fronczak, Fronczak en Holyst (2004) se presiese formulering van die gemiddelde pad in ER-netwerke $\left(L_{E R}\right)$, en Humphries en Gurney (2008) se kleinwêreldsheidindeks $(S)$, het aangetoon dat hutsmerknetwerke op Instagram ook kleinwêreldnetwerke is, mits 'n nie-zero oorganklikheid $(C)$ bestaan. Die implikasies daarvan om volksonomie as komplekse netwerke te bestudeer is dat aangetoon word dat wanneer mense etikette spontaan toeken aan sosiale media inhoud, dit met 'n vergelykbare struktuur gedoen word as wat ook in ander soorte netwerke aanwesig is.

Instagram is ' $n$ redelik nuwe platform en daar bestaan ' $n$ groot aantal fasette van Instagram wat nog nie ondersoek is nie. Diehuidige studiehet byvoorbeeld op kleinwêreldsheid gefokus, maar in navolging van Xamena, Brignole en Maguitman (2017) en Shen en Wu (2005) sou die skakelverspreiding van nodusse ook ondersoek kon word en vergelyk word met die skaalvrye netwerkmodel van Barabási en Albert (1999). Daar is ook nie spesifiek ondersoek ingestel na hoe maatskappye se hutsmerknetwerke onderling geskakel is nie, alhoewel toetse aangetoon het dat daar 'n groot mate van koppeling tussen maatskappye se hutsmerknetwerke is.

\section{Bibliografie}

Aslam S. 2020. Instagram by the numbers: Stats, demographics en fun facts. https://www.omnicoreagency.com/instagram-statistics/ (op 4 Mei 2020 geraadpleeg).

Barabási A-L \& Albert R. 1999. Emergence of scaling in random networks. Science, Volume 286:509-511.

Bergström T, Bäckman L. 2013. Marketing and PR in Social Media. How the utilization of Instagram builds and maintains customer relationships. Ongepubliseerde BA-skripsie: Stockholms Universitet.

Borge-Holthoefer J, Arenas A. 2010. Semantic networks: Structure and dynamics. Entropy, 12(5):1264-1302.

Cattuto C, Schmitz C, Baldassarri A, Servedio VD, Loreto V, Hotho A, et al. 2007. Network properties of folksonomies. Ai Communications, 20(4):245-262.

Dorsch I. 2018. Content description on a mobile image sharing service: Hashtags on Instagram. Journal of Information Science Theory and Practice, 6(2):46-61.
Erdös P, Rényi A. 1960. On the evolution of random graphs. Publications of the Mathematical Institute of the Hungarian Academy of Sciences, 5:17-61.

Erz A, Marder B, Osadchaya E. 2018. Hashtags: Motivational drivers, their use, and differences between influencers and followers. Computers in Human Behavior, $89: 48-60$

Estrada E. 2012. The structure of complex networks. Theory and applications. Oxford: Oxford University Press.

Fronczak A, Fronczak P, Holyst JA. 2004. Average path length in random networks. Physical Review E, 70:056110.

Giannoulakis S, Tsapatsoulis N. 2016. Evaluating the descriptive power of Instagram hashtags. Journal of Innovation in Digital Ecosystems, 3(2):114-129.

Heidtmann K. 2013. Internet-Graphen. Informatik_Spektrum, 6:440-448.

Himelboim I, Smith MA, Rainie L, Shneiderman B, Espina C. 2017. Classifying Twitter topic-networks using Social Network Analysis. Social Media + Society:1-13 [geen volume of uitgawe nie].

Humphries MD, Gurney K. 2008. Network 'small-world-ness': a quantitative method for determining canonical network equivalence. PloS one, 3(4):e0002051.

Ibba S, Orrù M, Pani FE, Porru S. 2015. Hashtag of Instagram: From folksonomy to complex network. s.l., s.n.:279-284.

Jaakonmäki R, Müller O, Vom Brocke J. 2017. The impact of content, context, and creator on user engagement in social media marketing. s.I., s.n.:1152-1160.

Kleintjes A. 2017. The Rise of the 'Instagram Economy' phenomenon in a South Africa: An exploration of how conspicuous consumption on Instagram contributes to brand value creation. Ongepubliseerde MA-verhandeling: Universiteit van Kaapstad.

Kolowich L. 2014. The history of Hashtags [Infographic]. https://blog.hubspot.com/ marketing/history-of-hashtags (op 1 Mei 2020 geraadpleeg).

Kusá D. 2018. The Born Frees as Assertive Citizens? Student Protests and Democratic Prospects in South Africa. Polish Political Science Yearbook, 47(4):722-741.

Latapy M, Magnien C, Del Vecchio N. 2008. Basic notions for the analysis of large two-mode networks. Social Networks, 30:31-48.

Li X, Zhang B. 2020. A Preliminary Network Analysis on Steam Game Tags: Another Way of Understanding Game Genres. Academic Mindtrek 2020 (AcademicMindtrek '20), January 29-30, 2020, Tampere, Finland. [geen bladsye].

Liang W, Shi Y, Tse CK, Liu J, Wang Y, Cui X. 2009. Comparison of co-occurrence networks of the Chinese and English languages. Physica A, 388:4901-4909.

Monechi B, Gravino P, Servedio VDP, Tria F, Loreto V. 2017. Significance and popularity in music production. Royal Society Open Science, 4:170433.

Newman MEJ. 2010. Networks. Oxford: Oxford University Press.

Noruzi A. 2006. Folksonomies: (Un)Controlled vocabulary? Knowledge Organization, 33(4):199-203.

Pan X, He S, Zhu X, Fu O. 2016. How users employ various popular tags to annotate resources in social tagging: an empirical study. Journal of the Association for Information Science and Technology, 67(5):1121-1137.

Peng G, Minett JW, Wang WS-Y. 2008. The networks of syllables and characters in Chinese. Journal of Quantitative Linguistics, 15(3):243-255.

Schnelle S. 2018. Kartlegging av maritime hybride trusler. Kan bruk av stordato og sosial nettverksanalyse bidra til økt maritim situasjonsbevissthet? Ongepubliseerde MA-verhandeling: Forsvarets høgskole.

Senekal BA. 2015. 'n Kwantifisering van kleinwêreldsheid in Afrikaanse kultuurnetwerke in vergelyking met ander komplekse netwerke. LitNet Akademies Natuurwetenskappe, 12(3):665-688.

Shen K, Wu L. 2005. Folksonomy as a complex network. arXiv:cs/0509072v1.

Solé RV, Corominas-Murtra B, Valverde S, Steels L. 2010. Language networks: Their structure, function, and evolution. Complexity, 15(6):20-26.

Terttunen A. 2017. The influence of Instagram on consumers' travel planning and destination choice. Ongepubliseerde BA-skripsie: Universiteit van Haaga-Helia.

Van der Wal T2007. Folksonomy Coinage and Definition. http://www.vanderwal. net/folksonomy.html (op 5 Mei 2020 geraadpleeg).

Watts DJ, Strogatz SH. 1998. Collective dynamics of 'small-world' networks. Nature, 393(6684):409-410.

Xamena E, Brignole NB, Maguitman A. 2017. A structural analysis of topic ontologies. Information Sciences, 421:15-29.

Ye Z, Hashim NH, Baghirov F, Murphy J. 2018. Gender differences in Instagram hashtag use. Journal of Hospitality Marketing en Management, 27(4):386404.

Zhou S, Hu G, Zhang Z, Guan J. 2008. An empirical study of Chinese language networks. Physica A, 387:3039-3047. 